\title{
CLINICAL TYPES, IOP CONTROL AND VISUAL OUTCOME IN LENS INDUCED GLAUCOMA
}

\author{
Venkataratnam Peram¹, Srihari Atti², Ramdas Paspula3, Krishnakisore Arikeri', Swathi Shiva ${ }^{5}$, Vani Marrevula
}

\begin{abstract}
${ }^{1}$ Assistant Professor, Department of Ophthalmology, Osmania Medical College, Sarojini Devi Eye Hospital, Hyderabad. ${ }^{2}$ Associate Professor, Department of Ophthalmology, Osmania Medical College, Sarojini Devi Eye Hospital, Hyderabad. ${ }^{3}$ Assistant Professor, Department of Ophthalmology, Osmania Medical College, Sarojini Devi Eye Hospital, Hyderabad. ${ }^{4}$ Assistant Professor, Department of Ophthalmology, Osmania Medical College, Sarojini Devi Eye Hospital, Hyderabad. ${ }_{5}^{5}$ Post Graduate, Department of Ophthalmology, Osmania Medical College, Sarojini Devi Eye Hospital, Hyderabad. ${ }^{6}$ Post Graduate, Department of Ophthalmology, Osmania Medical College, Sarojini Devi Eye Hospital, Hyderabad.
\end{abstract}

ABSTRACT: BACKGROUND: Lens Induced Glaucoma is a common cause of ocular morbidity.

OBJECTIVES: Our study was to know the clinical types, IOP control and Visual outcome in Lens Induced Glaucoma.

MATERIALS AND METHODS: This was a tertiary hospital based study in Glaucoma Clinic, Sarojini Devi Eye Hospital and Regional Institute of Ophthalmology (RIO), Osmania Medical College, Hyderabad over a period from March 2015 to August 2015. 50 Patients diagnosed as Lens Induced Glaucoma (LIG) clinically were studied. Visual acuity and intraocular pressure were assessed preoperatively and post-operatively. Post-operative complications were noted. The data was analyzed by simple statistical methods. RESULTS: This was a study of 50 patients diagnosed as Lens Induced Glaucoma (LIG) clinically. Age group distribution was $1(2.0 \%)$ in $40-50$ Yrs., $13(26.0 \%)$ in $>50-60$ Yrs., $26(52.0 \%)$ in $>60-70$ Yrs. and $10(20.0 \%)$ in $>70$ Yrs. Sex distribution was $23(46.0 \%)$ of Males and 27(54.0\%) of Females. The type of Lens induced Glaucoma was 39(78.0\%) of Phacomorphic Glaucoma and $11(22.0 \%)$ of Phacolytic (Lens Protein) Glaucoma. The Intraocular pressure was $<20 \mathrm{~mm} \mathrm{Hg}$ in no $(0.0 \%)$ case, $>20-40 \mathrm{~mm} \mathrm{Hg}$ in $18(36.0 \%),>40-60 \mathrm{~mm} \mathrm{HG}$ in $27(54.0 \%)$ and $>60 \mathrm{~mm}$ HG in 5(10.0\%) pre-operatively, and $<20 \mathrm{~mm}$ HG in $49(98.0 \%)$ and $>60 \mathrm{~mm}$ HG $1(2.0 \%)$ post-operatively. The Mean IOP was $42.12 \mathrm{~mm}$ of Hg pre-operatively and $12.56 \mathrm{~mm}$ HG post-operatively. The Range of IOP was 20-60 mm HG pre-operatively and 10-15mm HG post-operatively. Visual Acuity was PL +ve in $24(48.0 \%)$ and HM $-<3 / 60$ in $26(52.0 \%)$ with no cases $0(0.0 \%)$ in $>3 / 60$ pre-operatively, and 6/6-6/18 in $17(34.0 \%),<6 / 18-6 / 60$ in $27(54.0 \%),<6 / 60-3 / 60$ in $4(8.0 \%)$ and $<3 / 60-\mathrm{HM}$ in $2(4.0 \%)$ postoperatively at 6-8 weeks. Postoperative complications were Hyphema in $3(6.0 \%)$, Striate Keratopathy in $13(26.0 \%)$, Anterior Uveitis in $11(22.0 \%)$, Posterior tear with Vitreous loss in 5(10.0\%), Cortical remnants in $6(12.0 \%)$, Subluxation of IOL in $2(6.0 \%)$ and Optic atrophy in $6(12.0 \%)$.

CONCLUSIONS: This study showed Phacomorphic type as the common Lens induced glaucoma in a tertiary eye hospital and Manual small incision cataract surgery was effective in controlling IOP and achieving a good visual outcome.

KEYWORDS: Lens Induced Glaucoma, Phacomorphic, Phacolytic, Intraocular Pressure, Visual Acuity.

HOW TO CITE THIS ARTICLE: Venkataratnam Peram, Srihari Atti, Ramdas Paspula, Krishnakisore Arikeri, Swathi Shiva, Vani Marrevula. "Clinical Types, IOP Control and Visual Outcome in Lens Induced Glaucoma". Journal of Evolution of Medical and Dental Sciences 2015; Vol. 4, Issue 92, November 16; Page: 15798-15801, DOI: 10.14260/jemds/2015/2284.

INTRODUCTION: There are 20 million blind people in India and $80.0 \%$ of this blindness is due to preventable causes. ${ }^{1}$ Cataract in India is the most important cause of preventable blindness accounting to $63.7 \% .^{1}$ With a cataract backlog of around 12 million and increasing at an estimated rate of 3.8 million annually. ${ }^{1}$ the Lens induced secondary glaucoma, is not uncommon in India. In India, it is estimated that there are 11.2 million persons aged 40yrs. and older with Glaucoma in which the secondary glaucoma could affect 2.28 million. $^{2}$ clinically, several types of glaucoma which may occur in association with the formation of cataract are an important cause of secondary glaucoma. In India, Lens induced glaucoma is common, as the incidence of cataract cases far exceeds the total number of surgeries done currently. ${ }^{3}$

Financial or Other, Competing Interest: None.

Submission 28-10-2015, Peer Review 29-10-2015,

Acceptance 06-11-2015, Published 16-11-2015.

Corresponding Author:

Venkataratnam Peram

Srihari Atti, Glaucoma Clinic,

Sarojini Devi Eye Hospital,

Hyderabad-5000028,

Telangana, India

E-mail: ratnam_pv9@yahoo.com, srihariatti@gmail.com

DOI:10.14260/jemds/2015/2284.
Delayed treatment of senile cortical cataract leading to lens-induced glaucoma which compromises the function of the optic nerve due to rise of intraocular pressure remains as an important cause of irreversible loss of vision, especially so in the rural population.

Lens-induced glaucoma may be a secondary angleclosure or open-angle glaucoma and is diagnosed by the presence of eye pain, decreased vision, mature or hypermature cataract, angle closure or open, and increased intraocular pressure. In the great majority of cases, essentially two mechanisms are the important causes of Lens induced Glaucoma. The first type is a Phacomorphic secondary angle-closure pupillary block glaucoma due to senile cortical cataract intumescent stage. The second type is a phacolytic (Lens Protein) secondary open angle glaucoma due to trabecular meshwork obstruction due to the leakage of lens material through the capsule of a senile cortical cataract.

The immediate aim of treatment is to reduce the inflammation and the intraocular pressure with medical therapy. Definitive treatment is the removal of the cataractous lens, once the high intraocular pressure is satisfactorily controlled.4-7 In India, financial, cultural and psychosocial barriers in accessing excellent surgical services still exist. 
There is an increasing backlog of cataract due to the population explosion with increased life expectancy and suboptimal utilization of the easily available cataract surgical services by the rural community. So, lens induced glaucoma is a common cause of ocular morbidity.

METHODS: This was a hospital based study in the Glaucoma clinic, Sarojini Devi Eye Hospital and Regional Institute of Ophthalmology, Osmania Medical College (Govt.) Hyderabad over a period from March 2012 to August 2014. The study group was 50 Patients diagnosed as Lens Induced Glaucoma clinically. The study was approved by the institute ethical committee. The informed consent was taken from all the patients of the study group.

\section{METHODOLOGY:}

Inclusion Criteria: The study group was the patients who reported with acute onset of pain, gradual progressive loss of vision, redness, and watering as their presenting complaints and were diagnosed as Lens induced Glaucoma based on the clinical findings and increased intraocular pressure.

Exclusion Criteria: Cases with a primary open or closed angle glaucoma, secondary glaucoma due to traumatic cataract complicated cataract, Congenital cataract and secondary cataract were excluded.

A detailed clinical history was taken with the data of Age and Sex. Complete clinical examination of both eyes was done with slit lamp biomicroscopy, Snellen's Visual acuity, intraocular pressure (IOP) measurement by Goldman's applanation tonometer, Gonioscopy, Indirect Ophthalmoscopy and B scan and. Visual acuity and intraocular pressure (IOP) were assessed preoperatively and postoperatively. Postoperative complications were noted.

Phacomorphic glaucoma diagnosis was done based on the presence of corneal oedema, shallow anterior chamber, flare in the aqueous, fixed dilated pupil, intumescent cataractous lens, closed angle of the anterior chamber and increased intraocular pressure above $21 \mathrm{~mm} \mathrm{Hg}$. $^{4-7}$ Phacolytic (Lens Protein) glaucoma diagnosis was made by the presence of corneal edema, normal or deep anterior chamber, aqueous flare, prominent white material/particles in the anterior chamber, increased intraocular pressure, and evidence of a mature or hypermature cataract with or without white spots on the anterior capsule. . $^{4}$ Increased IOP was controlled with tab. Acetazolamide $250 \mathrm{mg}$ 4times a day, Timolol maleate $0.5 \%$ eye drops 2 times a day and $20.0 \%$ intravenous Mannitol in refractory cases. Dexamethasone $0.1 \%$ eye drops 4 times a day was given to reduce the inflammation. Once the intraocular pressure was controlled to a safe level, all the patients were undergone extracapsular cataract extraction with posterior chamber IOL implantation (ECCE with PC IOL).

The technique was Small Incision Cataract Surgery (SICS). All the cases were discharged on $3^{\text {rd }}$ postoperative day with the follow-up in $2^{\text {nd }}$ week and at 6-8 wks. Post operatively all the patients were put on a topical steroid and antibiotic combination of $0.1 \%$ Dexamethasone and Ciprofloxacin with a cycloplegic drug. During the follow-up visual acuity, anterior segment examination, tonometry and fundus examination were repeated. A good IOP control was defined as a postoperative IOP of $<21 \mathrm{~mm} \mathrm{Hg}$ without the need for any antiglaucoma drugs. Poor visual outcome was defined as the best corrected visual acuity of $<6 / 60$. All the data was analyzed by simple statistical methods.
RESULTS: The study group was 50 patients diagnosed as Lens Induced Glaucoma clinically. The presenting symptoms of ocular pain, defective vision, redness and watering of the eyes and the clinical signs of Circumciliary congestion, corneal edema and senile cortical cataractous lens with raised intraocular pressure (IOP) of $>21 \mathrm{~mm}$ were present. The visual acuity was reduced due to cataract and corneal edema secondary to a sudden rise of intraocular pressure.

\begin{tabular}{|c|c|c|c|c|c|}
\hline Sl. No. & Age in Yrs. & Male & Female & Total & $\%$ \\
\hline 1 & $>40-50$ & 0 & 1 & 1 & 2.0 \\
\hline 2 & $>50-60$ & 9 & 4 & 13 & 26.0 \\
\hline 3 & $>60-70$ & 11 & 15 & 26 & 52.0 \\
\hline 4 & $>70$ & 3 & 7 & 10 & 20.0 \\
\hline \multicolumn{2}{|c|}{ Total } & 23 & 27 & 50 & 100.0 \\
\hline & $\%$ & 46.0 & 54.0 & & \\
\hline \multicolumn{6}{|c|}{ Table 1: Age Distribution } \\
\hline
\end{tabular}

Age group distribution was $1(2.0 \%)$ in $40-50 y r s$. $13(26.0 \%)$ in $>50-60$ yrs., $26(52.0 \%)$ in $>60-70$ yrs. and $10(20.0 \%)$ in $>70 y$ rs. Sex distribution was $23(46.0 \%)$ of Males and 27(54.0\%) of Females. Lens induced glaucoma was common in $>60-70 y$ rs. with $26(56.0 \%)$ in both sexes.

\begin{tabular}{|c|c|c|c|}
\hline Sl. No. & Type & No. & $\%$ \\
\hline 1 & Phacomorphic & 39 & 78.0 \\
\hline 2 & Phacolytic (Lens Protein) & 11 & 22.0 \\
\hline \multicolumn{2}{|r|}{ Total } & 50 & 100.0 \\
\hline \multicolumn{4}{|c|}{ Table 2: Type of Lens Induced Glaucoma } \\
\hline
\end{tabular}

Table of type of Lens induced Glaucoma showed 39 cases (78.0\%) of Phacomorphic Glaucoma and 11 Cases (22.0\%) of Phacolytic (Lens Protein) Glaucoma.

\begin{tabular}{|c|c|c|c|c|c|}
\hline \multirow{2}{*}{ Sl. No. } & \multirow{2}{*}{ IOP (mmHg) } & \multicolumn{2}{|c|}{ Pre-operative } & $\begin{array}{c}\text { Post-operative } \\
\text { at 6 wks. }\end{array}$ \\
\cline { 3 - 6 } & & No. & $\%$ & No. & $\%$ \\
\hline 1 & $<20$ & 0 & 0.0 & 49 & 98.0 \\
\hline 2 & $>20-40$ & 18 & 36.0 & 0 & 0.0 \\
\hline 3 & $>40-60$ & 27 & 54.0 & 0 & 0.0 \\
\hline 4 & $>60$ & 5 & 10.0 & 1 & 2.0 \\
\hline \multicolumn{7}{|c|}{ Total } & $\mathbf{5 0}$ & $\mathbf{1 0 0 . 0}$ & $\mathbf{5 0}$ & $\mathbf{1 0 0 . 0}$ \\
\hline Range & \multicolumn{3}{|c|}{$20-60$} & \multicolumn{2}{|c|}{$10-15$} \\
\hline \multicolumn{7}{|c|}{ Mean } & \multicolumn{2}{|c|}{ Table 3: Intraocular Pressure (IOP) } \\
\hline
\end{tabular}

This Table of Intraocular pressure showed $<20 \mathrm{~mm} \mathrm{Hg}$ in no $(0.0 \%)$ case, $>20-40 \mathrm{~mm} \mathrm{Hg}$ in $18(36.0 \%),>40-60 \mathrm{~mm}$ HG in $27(54.0 \%)$ and $>60 \mathrm{~mm} \mathrm{HG}$ in $5(10.0 \%)$ pre-operatively and $<20 \mathrm{~mm}$ HG in $49(98.0 \%)$ and $>60 \mathrm{~mm} \mathrm{HG} 1(2.0 \%)$ postoperatively. The Mean IOP was $42.12 \mathrm{~mm} \mathrm{Hg}$ pre operatively and $12.56 \mathrm{~mm}$ HG postoperatively. The Range of IOP was $20-60 \mathrm{~mm}$ HG preoperatively and $10-15 \mathrm{~mm}$ HG postoperatively.

\begin{tabular}{|c|c|c|c|c|c|}
\hline \multirow{2}{*}{ Sl. No. } & \multirow{2}{*}{ Snellen's VA } & \multicolumn{2}{|c|}{ Pre-operative } & \multicolumn{2}{|c|}{$\begin{array}{c}\text { Post-operative } \\
\text { at } 6 \text { wks. }\end{array}$} \\
\hline & & No. & $\%$ & No. & $\%$ \\
\hline 1 & No PL & 0 & 0.0 & 0 & 0. \\
\hline 2 & $\mathrm{PL}+\mathrm{ve}$ & 24 & 48.0 & 0 & 0.0 \\
\hline 3 & $<3 / 60-\mathrm{HM}$ & 26 & 52.0 & 2 & 4.0 \\
\hline 4 & $3 / 60-<6 / 60$ & 0 & 0.0 & 4 & 8.0 \\
\hline 5 & $6 / 60-<6 / 18$ & 0 & 0.0 & 27 & 54.0 \\
\hline \multirow[t]{2}{*}{6} & $6 / 18-6 / 6$ & 0 & 0.0 & 17 & 34.0 \\
\hline & Total & 50 & 100.0 & 50 & 100.0 \\
\hline \multicolumn{6}{|c|}{ Table 4: Visual Acuity } \\
\hline
\end{tabular}


Table of Visual Acuity showed preoperatively PL +ve in $24(48.0 \%)$ and $\mathrm{HM}-<3 / 60$ in $26(52.0 \%)$ with no cases $0(0.0 \%)$ in $>3 / 60$ preoperatively and $6 / 6-6 / 18$ in $17(34.0 \%)$, $<6 / 18-6 / 60$ in $27(54.0 \%),<6 / 60-3 / 60$ in $4(8.0 \%)$ and $<3 / 60$-HM in $2(4.0 \%)$ postoperatively at 6 weeks.

\begin{tabular}{|c|c|c|c|}
\hline Sl. No. & Complications & No. & $\%$ \\
\hline 1 & Hyphema & 3 & 6.0 \\
\hline 3 & Striate Keratopathy & 13 & 26.0 \\
\hline 4 & Anterior Uveitis & 11 & 22.0 \\
\hline 5 & $\begin{array}{c}\text { Posterior Capsular Tear with } \\
\text { Vitreous Loss }\end{array}$ & 5 & 10.0 \\
\hline 6 & Cortical Remnants & 6 & 12.0 \\
\hline 7 & Subluxation of IOL & 2 & 6.0 \\
\hline 8 & Optic Atrophy & 6 & 12.0 \\
\hline \multicolumn{4}{|c|}{ Table 5: Post-Operative Complications } \\
\hline
\end{tabular}

Table of Postoperative complications showed Hyphema in $3(6.0 \%)$, Striate Keratopathy in $13(26.0 \%)$, Anterior Uveitis in 11(22.0\%), Posterior tear with Vitreous loss in $5(10.0 \%)$, Cortical remnants in $6(12.0 \%)$, Subluxation of IOL in 2(6.0\%) and Optic Atrophy in 6(12.0).

DISCUSSION: Cataract is the most important cause of curable blindness in India, affecting mostly the older rural population. Lens induced glaucoma develops when a long standing senile cortical cataract becomes mature or hypermature. Late and delayed treatment of cataract leads to Lens Induced Glaucoma, especially so in the rural population, though Cataract surgery is a very rewarding surgery. Lens Induced Glaucoma is a preventable and curable condition. It is still prevalent in India, in spite of easy availability of cataract surgical facilities under the National Programme for Control of Blindness (NPCB) with Government Organizations, NGOs and private practitioners.

Lens induced glaucoma is a clinical condition with the characteristics of (1) a secondary glaucoma (Resembling acute angle closure glaucoma) in one eye with senile cortical cataract usually mature or hyper-mature (Rarely immature), (2) normal intraocular pressure with an open angle in the other eye, and (3) a prompt relief of symptoms and signs with an improvement of vision after cataract extraction. Lens induced glaucoma may be phacomorphic or phacolytic (Lens Protein). Though phacomorphic and phacolytic (Lens Protein) are clinically distinct types, they have certain common features in that 1) they are lens induced, 2) they compromise the function of the optic nerve due to increased intraocular pressure and 3) cataract surgery is curative in these. Phacomorphic is more often encountered in clinical practice and presents as an angle closure glaucoma due to pupillary block. Phacolytic (Lens Protein) presents as open angle glaucoma due to trabecular meshwork obstruction. ${ }^{4-7}$

Our study age distribution of $2.0 \%$ in $40-50$ yrs., $26.0 \%$ in $>50-60$ yrs., $52.0 \%$ in $>60-70$ yrs. and $20.0 \%$ in $>70$ yrs. correlates with the study of Raghunandan Kothari et al. ${ }^{8}$ of $6.0 \%$ in $51-60 y r s, 66.0 \%$ in $61-70$ yrs., $26.0 \%$ in $71-80 y$ rs and $2.0 \%$ in $>80 \mathrm{yrs}$ with the age range of 56 to $81 \mathrm{yrs}$ with a mean of 68.84 yr., the study of Payal Gupta et al. ${ }^{10}$ of $24.0 \%$ $<60$ years, $56.0 \%$ in $61-70$ years and $20.0 \%$ in $>70$ years and the study of Mohindar Singh et al. ${ }^{14}$ of age range of 49 to 77 years with a mean of $64.5 y$ rs. There was more number of patients in $>60-70$ yrs. with $52.0 \%$ in our study which correlates with $66.0 \%$ in the study of Raghunandan Kothari et $\mathrm{al}^{4}$ and $56.0 \%$ in the study of Payal Gupta et al. ${ }^{10}$
Our study sex distribution of $54.0 \%$ of Females and $46.0 \%$ of Males with the ratio of $1.2: 1$ correlates with $64.0 \%$ of Females and $36.0 \%$ of Males with the ratio of $1.8: 1$ in the study of Raghunandan Kothari et $\mathrm{al}^{8}, 70.0 \%$ Females and $30.0 \%$ Males with a ratio of 2.3:1 in the study of Ramakrishnan et al, ${ }^{9} 56.0 \%$ Females and $44.0 \%$ Males with the ratio of $1.3: 1$ in the study of Payal Gupta et al, $1055.0 \%$ of Females and $45.0 \%$ of Males with the ratio of $1.3: 1$ in the study of Rijal AP et al. ${ }^{12}$ and $59.0 \%$ Females and $41.0 \%$ with the ratio 1.5:1 in the study of Mohindar singh et al. ${ }^{14}$ So, our study correlates with the other studies that the Females were affected more than the Males because of the socio-economic and cultural factors playing a role leading to negligence with late presentation of cataract in females.

In our study, Intraocular pressure $(\mathrm{mm} \mathrm{Hg})$ at clinical presentation showed no case $(0.0 \%)$ in $<20 \mathrm{~mm} \mathrm{Hg}, 36.0 \%$ in $>20-40 \mathrm{mmHg}, 54.0 \%$ in $>40-60 \mathrm{~mm} \mathrm{Hg}$ and $10.0 \%$ in $>60 \mathrm{~mm}$ $\mathrm{Hg}$. Our study mean IOP of $42.12 \mathrm{~mm}$ of $\mathrm{Hg}$ correlates with the mean IOP of $44 \mathrm{~mm} \mathrm{Hg}$ (Range of $24-68 \mathrm{~mm} \mathrm{Hg}$ ) in the study of Raghunandan Kothari et al. ${ }^{8}$ mean IOP of $38.4 \mathrm{~mm}$ Hg in the study of R. Ramakrishnan et al. ${ }^{9}$ the mean of $42.5 \mathrm{~mm} \mathrm{Hg}$ (Range of 59.1-33mm Hg) in the study of Payal Gupta et al. ${ }^{10}$ the IOP range of $24.0-59.0 \mathrm{~mm} \mathrm{Hg}$ in the study of Rijal AP et $\mathrm{al}, 12$ the mean IOP of $44 \mathrm{~mm} \mathrm{Hg}$ (Range $24-68 \mathrm{~mm} \mathrm{Hg}$ ) in the study of Mohindar singh et al. ${ }^{14}$ and $>30 \mathrm{~mm} \mathrm{Hg}$ in $79.0 \%$ in the study of D Pradhan et al.11 So, the mean IOP was around $40 \mathrm{~mm} \mathrm{Hg}$ in the clinical presentation of our study and in other studies.

In our study, Snellen's Visual Acuity at clinical presentation was PL +ve in $48.0 \%$ and $\mathrm{HM}-<3 / 60$ in $52.0 \%$ with no cases $(0.0 \%)$ in VA of $>3 / 60$. Our study Visual Acuity correlates with the studies of, Raghunandan Kothari et al. ${ }^{8}$ of PL +Ve in 78.0\% and PL doubtful in 6.0\%, Payal Gupta et al. ${ }^{10}$ of hand movement close to face or less and none of the patient had faulty light projection, Mohindar singh et al. ${ }^{14}$ of PL +ve in $90.0 \%$ and PL doubtful in 5.0\%. And D Pradhan et al. ${ }^{11}$ of $\mathrm{HM}$ or less. So, the visual acuity in the clinical presentation of LIG was $<3 / 60$ in majority of the cases in our study and in all other studies.

Our study of the type of Lens induced Glaucoma of $78.0 \%$ of Phacomorphic and $22.0 \%$ of Phacolytic (Lens Protein) correlates with $78.0 \%$ phacomorphic and $22.0 \%$ phacolytic in the study of Raghunandan Kothari et al. ${ }^{8} 60.0 \%$ phaco-morphic and $40.0 \%$ phacolytic in the study of Payal Gupta et al. ${ }^{10} 72.0 \%$ phacomorphic and $28.0 \%$ phacolytic in the study of D Pradhan et al. ${ }^{11} 65.0 \%$ Phacomorphic and $35.0 \%$ phacolytic in the study of Rijal AP et al. ${ }^{12}$ and $53.0 \%$ phacomorphic and $47.0 \%$ phacolytic in the study of Prajna N et al. ${ }^{13}$ So, our study correlates with the all the above studies in that the Phacomorphic type was more common than the Phacolytic type.

In our study postoperative IOP was $<20 \mathrm{~mm} \mathrm{Hg}$ in $49(98.0 \%)$ and $>60 \mathrm{~mm}$ HG $1(2.0 \%)$ with a mean of $12.56 \mathrm{~mm}$ $\mathrm{Hg}$ in the range of $10-5 \mathrm{~mm} \mathrm{Hg}$. So, In our study all the patients had a normal postoperative IOP of $<20 \mathrm{~mm} \mathrm{Hg}$ without any additional antiglaucoma drugs which correlates well with the other studies of $21 \mathrm{~mm} \mathrm{Hg}$ or less in $87.0 \%$ of D. Pradhan et al. ${ }^{11}$ ranged from $14-22 \mathrm{mmHg}$ in Rijal AP et al. ${ }^{12}$ $12.7 \pm 2.4 \mathrm{~mm} \mathrm{Hg}$ in R Ramakrishnan et al. ${ }^{9}<20 \mathrm{~mm} \mathrm{Hg}$ in Payal Gupta et al. ${ }^{10}$ Prajna N et al. ${ }^{13}$ and Mohindar Singh et al. ${ }^{14}$

Postoperative visual Acuity at 6 weeks in our study was $6 / 18-6 / 6$ in $34.0 \%,<6 / 18-6 / 60$ in $54.0 \%,<6 / 60-3 / 60$ in $8.0 \%$ and $<3 / 60-\mathrm{HM}$ in $4.0 \%$, in Prajna $\mathrm{N}$ et al. ${ }^{13}$ was $>6 / 60$ in $88.0 \%$ and $<6 / 60$ in $12.0 \%$, in Payal Gupta et al. ${ }^{10}$ was $6 / 12$ 
in $24.0 \%$, upto $6 / 60$ in $64 \%$ and $<6 / 60$ in $12.0 \%$. Our study visual acuity of $>6 / 60$ postoperatively in $92.0 \%$ correlates well with $88.0 \%$ of Prajna N et al. ${ }^{13}$ and $92.0 \%$ of Payal Guptal et al.10 Our study does not correlate with the Raghunandan Kothari et al..$^{8}$ of $6 / 18$ or better in $16.0 \%,<6 / 18-6 / 60$ in $24.0 \%,<6 / 60 \mathrm{PL}+$ ve in $56 \%$ and total blindness (No PL) in $4 \%$ D. Pradhan et al. ${ }^{11}$ of $6 / 60$ or better in $38.6 \%,<6 / 60$ $3 / 60$ in $31.2 \%$, and $<3 / 60$ in $30.2 \%$, Rijal AP et al. ${ }^{12}$ of $6 / 12$ $6 / 60$ in $45.0 \%$ and $<6 / 60$ in $30.0 \%$, as they achieved $>6 / 60$ in $40.0 \%, 38.6 \%$ and $45.0 \%$ respectively.

Our study Postoperative complications were Hyphema in $6.0 \%$, Striate Keratopathy in $26.0 \%$, Anterior Uveitis in $22.0 \%$, Posterior capsular tear with Vitreous loss in $10.0 \%$, Cortical remnants in $12.0 \%$ and Subluxation of IOL in $6.0 \%$. Our study correlates with the Raghunandan Kothari et al. 8 in terms of posterior capsular tear in $10.0 \%$, cortical remanats in $6.0 \%$, Anterior Uveitis in $33.3 \%$ and striate keratopathy in $24.6 \%$, with R Ramakrishnan et al. ${ }^{9}$ in terms of $24.0 \%$ corneal edema and with D Pradhan et al. ${ }^{11}$ in terms of $26.6 \%$ Anterior Uveitis and $25.5 \%$ Corneal edema. In our study there was optic atrophy in $12.0 \%$ which correlates with $8.0 \%$ of Payal Gupta et al. ${ }^{10}$ but not with $34.0 \%$ of D Pradhan et a. $1^{9}$

CONCLUSIONS: Phacomorphic Lens induced glaucoma was common in our tertiary level eye hospital. Manual small incision cataract surgery was effective in controlling IOP and achieving a good visual outcome with minimal complications due to the availability of modern medical and surgical techniques. There is a need to educate the patient about the dangers of lens-induced glaucoma.

\section{REFERENCES:}

1. Government of India, National Survey on Blindness and Visual Outcome after Cataract Surgery, 2001-2002, vol. 77, National Programme for Control of Blindness, Ministry of Health, Government of India, New Delhi, India, 2002.

2. George R, Ramesh Ve, Vijaya L. Glaucoma in India:Estimated Burden of Disease. J Glaucoma 2010; 19:391397.

3. Jain IS, Gupta A, Dogra MR, Gangwar DN, Dhir SP. Phacomorphic glaucoma Management and visual prognosis. Ind J Ophthalmol 31:648-653, 1983.
4. Richter C, Epstein DL. Lens-induced open-angle glaucoma. In: Ritch R, Shields MB, Krupin T, eds. The Glaucomas. 2nd ed. St Louis: Mosby; 1996.

5. Kanski J, Brad Bowling. Lens-related glaucoma. In: kanski J, Brad Bowling, eds. Clinical Ophthalmology: A systematic approach. 7th ed. Elsevier Saunders; 2011.

6. Sowka J. Phacomorphic glaucoma: case and review. Optometry. 2006 Dec; 77(12):586-9.

7. Papaconstantinou D, Georgalas I, Kourtis N, Krassas A, Diagourtas A, Koutsandrea C, Georgopoulos G. Lensinduced glaucoma in the elderly. Clin Interv Aging. 2009; 4:331-6.

8. Raghunandan Kothari, Sandeep Tathe, Pratik Gogri, and Akshay Bhandari. Lens-Induced Glaucoma: The Need to Spread Awareness about Early Management of Cataract among Rural Population ISRN Ophthalmology Volume 2013 (2013), Article ID 581727, 3 pages.

9. R Ramakrishanan, Devendra Maheshwari, Mohideen Abdul Kader, Rita Singh, Neelam Pawar, and M Jayahar Bharathi. Visual prognosis, intraocular pressure control and complications in phacomorphic glaucoma following manual small incision cataract surgery. Indian J Ophthalmol. 2010 Jul-Aug; 58(4): 303-306.

10. Payal Gupta, Sudhir Bhagotra, Suraj PrakashPattern and Visual Outcome in Lens Induced GlaucomaVol. 14 No. 4, Oct -December 2012 www.jkscience.org 181-84.

11. Pradhan D, Hennig A, Kumar J, Foster A. A prospective study of 413 cases of lens induced glaucoma in Nepal. Ind J Ophthalmol 2001; 49:103-7.

12. Rijal AP ${ }^{1}$, Karki DB. Visual outcome and IOP control after cataract surgery in lens induced glaucomas. Kathmandu University Medical Journal 01/2006; 4(1):30-3. 2006 JanMar; 4(1):30-3.

13. Prajna N, Ramakrishnan R, Krishnadas R, Manoharan N, et al. Lens induced glaucoma - Visual results and risk factors for final visual acuity. Indian J Ophthalmol 1996; 44:14-155.

14. Mohinder Singh, Hassan Al-Arrayyed, Revathy Krishnan, Intraocular Lens Implantation in Phacomorphic Glaucoma. Bahrain Medical Bulletin, Vol.24, No.3, September 2002; 24(3):88-90. 